\title{
A Comparative Study of Four Methods for the Detection of Nematode Eggs and Large Protozoan Cysts in Mandrill Faecal Material
}

\author{
Hanae Pouillevet $^{a} \quad$ Serge-Ely Dibakou ${ }^{c}$ Barthélémy Ngoubangoye ${ }^{d}$ \\ Clémence Poirotte $^{\mathrm{b}}$ Marie J.E. Charpentier ${ }^{\mathrm{b}}$ \\ ${ }^{a}$ Ecole Nationale Vétérinaire de Nantes - Oniris, Nantes, and ${ }^{b}$ Institut des Sciences \\ de I'Evolution, UMR 5554, Montpellier, France; ' SODEPAL, Bakoumba, and d Centre \\ de Primatologie, Centre International de Recherche Médicale de Franceville (CIRMF), \\ Franceville, Gabon
}

\section{Keywords}

Sedimentation - Flotation - Faecal egg counting technique - McMaster technique • Zoonotic enteric parasites · Mandrillus sphinx

\begin{abstract}
Coproscopical methods like sedimentation and flotation techniques are widely used in the field for studying simian gastrointestinal parasites. Four parasites of known zoonotic potential were studied in a free-ranging, non-provisioned population of mandrills (Mandrillus sphinx): 2 nematodes (Necator americanus/Oesophagostomum sp. complex and Strongyloides sp.) and 2 protozoan species (Balantidium coli and Entamoeba coli). Different coproscopical techniques are available but they are rarely compared to evaluate their efficiency to retrieve parasites. In this study 4 different field-friendly methods were compared. A sedimentation method and 3 different McMaster methods (using sugar, salt, and zinc sulphate solutions) were performed on 47 faecal samples collected from different individuals of both sexes and all ages. First, we show that McMaster flotation methods are appropriate to detect and thus quantify large protozoan cysts. Second, zinc sulphate McMaster flotation allows the retrieval of a higher number of parasite taxa compared to the other 3 methods. This method further shows the highest probability to detect each of the studied parasite taxa. Altogether our results show that zinc sulphate McMaster flotation appears to be the best technique to use when studying nematodes and large protozoa.

○ 2017 S. Karger AG, Basel
\end{abstract}

KARGER $\quad$ @ 2017 S. Karger AG, Basel
$\begin{aligned} & \text { E-Mail karger@karger.com } \\ & \text { www.karger.com/fpr }\end{aligned}$




\section{Introduction}

The close phylogenetic relationship between humans and non-human primates results in a high potential for pathogen exchanges between taxa [Wolfe et al., 1998; Miller and Fowler, 2014], and, as such, they share many parasitic, fungal, bacterial, and viral diseases [Whittier et al., 2000; Cibot et al., 2015]. Several cases of cross-species transmissions have been reported between humans and non-human primates, including viruses [Köndgen et al., 2008; Li et al., 2010], bacteria [Rwego et al., 2008; Wolf et al., 2014], blood-borne parasites [Standley et al., 2012], and intestinal parasites [Rwego et al., 2008; Hasegawa et al., 2014; Cibot et al., 2015]. Moreover, the risk of cross-species transmission is increasing because humans and non-human primates share more and more the same habitat [Legesse and Erko, 2004; Krief et al., 2010; Keita et al., 2014; Cibot et al., 2015; Narat et al., 2015], leading to water and food contamination [Legesse and Erko, 2004; Schuster and Visvesvara, 2004; Mossoun et al., 2015] or vector-borne disease transmission [Keita et al., 2014]. For example, zoonotic infections (pathogen agents that cross the barrier between humans and animals) were evidenced for intestinal parasites [Levecke et al., 2015] and herpesvirus [BurgosRodriguez, 2011] via physical contacts between humans and non-human primates, spumavirus such as simian foamy virus via exposure to simian fluids [Greger, 2007], and malaria [Galinski and Barnwell, 2009] via an intermediary host (mosquito bites). There is also the potential for zoonotic disease transmission through hunting and handling bushmeat: the butchering of chimpanzees is currently considered the most likely source for HIV-1, the strain of the AIDS virus that has spread around the world [Sharp and Hahn, 2011], and human outbreaks of Ebola haemorrhagic fever have been traced to exposure to the dead bodies of infected chimpanzees and gorillas [Muyembe-Tamfum et al., 2012].

Concerning zoonotic enteric parasites, direct transmission via the faecal/oral route is likely to be the most common form of transmission between humans and non-human primates [Thompson and Smith, 2011]. Because of the important public health implications, several studies have investigated gastrointestinal parasitism in non-human primates, including African apes [Ashford et al., 1990, 2000; Cibot et al., 2015; Narat et al., 2015] and cercopithecoids, such as baboons and mandrills [Benavides et al., 2012; Ebbert et al., 2015; Kouassi et al., 2015; Poirotte, 2016].

In the field, non-invasive methods are sometimes the only tools available to better understand patterns of infectious diseases and the current health status of wild animal populations [Jolles et al., 2008; Krief et al., 2008]. As such, coproscopical methods - based on non-invasive faecal material - can be easily implemented in different field conditions. These methods allow the detection of gastrointestinal nematodes and protozoa, and the estimation of parasite abundance within individual hosts as well as parasite prevalence [Krief et al., 2008; Kouassi et al., 2015; Lynsdale et al., 2015; Poirotte et al., 2016], albeit the adult worm burden is more difficult to assess due to many factors related to host immunity, health status, or parasite excretion rhythm, affecting the number of parasite eggs contained in host faecal material [Gillespie, 2006]. Two different techniques are commonly used for coproscopical analyses: sedimentation and flotation methods [Deluol, 1988; Kouassi et al., 2015; Peter et al., 2015; Becker et al., 2016; Chakraborty et al., 2016; Hyuga and Matsumoto, 2016]. Sedimentation techniques rely on the use of a low-density solution into which parasite forms fall. Centrifugation may be used in parallel to concentrate parasite forms. 
Sedimentation techniques allow the detection of many different gastrointestinal parasites, including small ones for which microscopic identification requires a large lens, such as Entamoeba sp. cysts [Poirotte et al., 2016] or Giardia sp. cysts [Peter et al., 2015]. Conversely, flotation methods rely on the use of dense solutions: using an appropriate specific gravity (SG in $\mathrm{g} / \mathrm{mL}$ ), fewer dense parasite forms may float while most of the vegetal debris falls. Therefore this method allows microscopic detection and parasite quantification (i.e., number of eggs per gram) of helminth eggs by concentrating them on the surface of the fluid. Flotation may be preceded by a first stage of centrifugation (direct centrifugal flotation - DCF - methods) or not (simple flotation - SF - methods). In order to quantify parasite eggs, SF methods are further used in combination with a McMaster method [Great Britain Ministry of Agriculture, Fisheries and Food, 1971; Henriksen and Aagaard, 1976; Thienpont et al., 1986] which is inexpensive and easily replicable. These methods are among the most frequently employed methods used in wildlife parasitology [Coles et al., 1992; Gillespie, 2006]. Different flotation media, from simple table salt and sugar [Hyuga and Matsumoto, 2016] to other chemicals, such as zinc sulphate [Becker et al., 2016], magnesium sulphate [Quinn et al., 1980; da Silva et al., 2009], sodium chloride and sodium nitrate [Mbaya and Udendeye, 2011; Crawley et al., 2016; Hu et al., 2016], or a combination of different solutions, such as salt-sugar solution [Gotfred-Rasmussen et al., 2016], have been examined for their potential usefulness in the flotation procedure. Mixed results have been found in the literature, and no consensus has been reached so far to determine the best way to detect gastrointestinal parasites in animals' faecal material, although the best method may vary across species and conditions.

Taking into consideration both issues of detecting zoonotic enteric parasites in non-human primates and selecting a coproscopical technique to use in the field, the aim of this study was to evaluate the efficiency of 4 field-friendly methods to retrieve nematode eggs and protozoan cysts of known zoonotic potential in a free-ranging, non-provisioned population of mandrills (Mandrillus sphinx). We compared therefore a sedimentation method with 3 different SF methods combined with a McMaster technique (thereafter "SF-Mc") using 3 historically widely used flotation solutions [Foreyt, 2013]. We focused on 2 nematodes and 2 protozoan species of known zoonotic potential: Necator americanus/Oesophagostomum sp. complex [Yelifari et al., 2005; Ghai et al., 2014], Strongyloides sp. [Yelifari et al., 2005; Vadlamudi et al., 2006], Entamoeba coli [Becker et al., 2011; Barda et al., 2013], and Balantidium coli [Arean and Koppisch, 1956; Whittier et al., 2000; Centers for Disease Control and Prevention, 2016a] retrieved from 47 faecal samples collected from the population.

In humans, hookworm infection, such as $N$. americanus, can cause itching and a localized rash [Georgiev, 2000]. Heavily infected patients may even experience abdominal pain, diarrhoea, loss of appetite, weight loss, fatigue, and anaemia [Georgiev, 2000]. Concerning Oesophagostomum sp. infection, acute pain in the abdomen is the most common manifestation in humans - mimicking appendicitis - but the disease can also be lethal to chimpanzees [Krief et al., 2008, 2010; Centers for Disease Control and Prevention, 2016b]. Wild-born great apes develop clinical signs of oesophagostomosis as soon as they are detained in captivity while the presence of the same parasites often remains asymptomatic in wild animals [Krief et al., 2008]. The large majority of humans infected with Strongyloides do not develop any symptom but some people may develop abdominal pain, bloating, heartburn, intermittent episodes of diarrhoea and constipation, a dry cough, and rashes [Toledo et al., 2015; Centers for

346

Folia Primatol 2017;88:344-357 DOI: $10.1159 / 000480233$
Pouillevet/Dibakou/Ngoubangoye/Poirotte/ Charpentier 
Disease Control and Prevention, 2016c]. These parasites are also known to cause pulmonary and intestinal injuries in non-human primates and can even lead to a lethal infection in some individuals [Mati et al., 2014]. In humans, B. coli infects the large intestine and produces infective microscopic cysts. The infection is mostly asymptomatic but people who are immunocompromised are likely to experience diarrhoea, dysentery, abdominal pain, weight loss, nausea, and vomiting. If left untreated, perforation of the colon may occur until death. Finally, Entamoeba sp. may cause similar symptoms if not asymptomatic [Schuster and Ramirez-Avila, 2008; Centers for Disease Control and Prevention, 2016a]. In primates, infection by these gastrointestinal protozoa may cause watery diarrhoea, haemorrhagic dysentery, extra-intestinal pathologies, such as liver abscesses, and even death [Levecke et al., 2007].

The prevalence of these 4 taxa is known to vary from $13.9 \%$ (Strondyloides sp.) to $73.8 \%$ (B. coli; see Table 5 in Poirotte et al. [2016]) in the studied mandrills. We hypothesized that sedimentation would allow the detection of a greater diversity of parasite taxa, as this technique is likely to concentrate a wider range of parasite taxa than SF-Mc techniques, which require solutions of appropriate density to make parasite forms float. We also hypothesized that a greater quantity of parasite eggs and cysts would be recovered with the sugar solution because of its higher density compared to the other 2 solutions.

\section{Materials and Methods}

\section{Ethics}

This study is based on a non-invasive collection of biological material and complies with ethical protocols approved by the CENAREST institution (authorization No.: AR0001/14/ MESRSC/CENAREST/CG/CST/CSAR). This research adhered to the legal requirements of Gabon for the ethical treatment of non-human primates.

\section{Study Population}

We studied a free-ranging, non-provisioned population of mandrills living in a fenced private park (Lékédi Park), near the village of Bakoumba, in Southern Gabon. This study group was founded in 2002 when 36 individuals, originating from a semi-captive population housed at CIRMF (Centre International de Recherches Médicales de Franceville), were released into the park [Peignot et al., 2008]. A second release event occurred in 2006 with 29 additional animals. In 2003, wild males joined the group and females gave birth during the first postrelease year. In July 2015, the group was composed of a total of 125 individuals, including more than $85 \%$ of wild-born animals habituated to human presence [Brockmeyer et al., 2015]. Since early 2012, the group has been followed every day from 6 a.m. to 6 p.m. by field assistants [Brockmeyer et al., 2015]. During daily behavioural monitoring of the population, human observers collected fresh faecal samples.

Faecal Sampling and Parasite Diagnoses

A total of 47 faecal samples was collected and analysed between July 2015 and October 2015. Among these 47 samples, 30 were opportunistically collected from unknown individuals while following the study group. The 17 remaining samples were collected from 8 male and 8 female mandrills ( 1 female was sampled twice over the study period) of the group aged 1.4-20.3 years. Whole faecal boluses were collected and mixed thoroughly before analysis. Sampled faecal material was stored at $4^{\circ} \mathrm{C}$, within $6 \mathrm{~h}$ following collection. Sample analysis never occurred later than 3 days after sampling. We identified eggs from the 2-nematode N. americanus/Oesophagostomum sp. complex (eggs of the two species are morphologically indistinguishable) and Strongyloides sp. using indicative characteristics such as the form, length, colour, the nature of the egg shell, and the appearance of the egg content [Euzeby, 1982; Deluol, 1988]. Cysts from the 2 protozoa B. coli and E. 
coli were diagnosed according to their typical morphological characteristics (see Table 2 in Poirotte et al. [2016]). The studied mandrills were also infected with other nematode and protozoan species [Poirotte et al., 2016] but we did not study them because they were absent in the studied samples.

Coproscopical Analyses

We used the 4 different methods, all 4 on the same day, on each of the 47 faecal samples by weighing $1 \mathrm{~g}$ of humid faeces, after homogenization of the entire faecal bolus.

For the sedimentation method, $1 \mathrm{~g}$ of faecal material and $6 \mathrm{ml}$ of Bailenger solution $(15 \mathrm{~g}$ sodium acetate, $3.60 \mathrm{~mL}$ acetic acid, $1,000 \mathrm{~mL}$ distilled water) were mixed with a tongue depressor in a Parasep filter faecal concentrator tube and then vortexed. The homogenized solution was then centrifuged at 1,500 rpm for $3 \mathrm{~min} ; 4 \mathrm{~mL}$ of the supernatant were removed, and the remaining pellet was resuspended. A $20-\mu \mathrm{L}$ drop of the homogenized pellet was deposited on a slide for microscopic analyses, and $60 \mu \mathrm{L}$ of physiological serum were added. We examined the slide using the $10 \times$ and $40 \times$ objective lenses.

The McMaster counting slide is composed of two chambers that can be filled with suspensions of faecal samples mixed with a given volume of flotation solution. These 2 chambers are marked with a grid (composed of 6 lines) on the inferior face of the superior slide. Thus, using a flotation medium showing a higher density than that of the studied parasite forms allows the latter to adhere to the inferior face of the superior slide, while debris fall to the bottom of the chamber. Eggs are then counted within the engraved area of both chambers. By knowing the concentration of the solution "faeces/flotation liquid" used to fill the chambers of the McMaster slide, a multiplication factor can be applied to estimate the number of eggs per gram of faeces [Foreyt, 2013]. In this study, we compared 3 different flotation solutions for their ability to recover nematode eggs and protozoan cysts from mandrills' faeces. A saturated salt solution was obtained by adding 400 $\mathrm{g}$ of $\mathrm{NaCl}$ to $1,000 \mathrm{~mL}$ of distilled water solution (SG: 1.18, Willis' liquid [Foreyt, 2013]), a saturated sugar solution was obtained by diluting $454 \mathrm{~g}$ of granulated sugar with $355 \mathrm{~mL}$ of distilled water (SG: 1.27, Sheather's sugar [Foreyt, 2013]), and a zinc sulphate solution was obtained by adding $371 \mathrm{~g}$ of $\mathrm{ZnSO}_{4}$ to $1,000 \mathrm{~mL}$ of distilled water (SG: 1.18, Faust's liquid [Foreyt, 2013]). First, we mixed $1 \mathrm{~g}$ of faecal material with $15 \mathrm{~mL}$ of the chosen flotation solution. The mixture was then filtered with a dry pad on a strainer, and the suspension was immediately transferred to a 2-chamber McMaster counting slide by filling both chambers. After $5 \mathrm{~min}$, we counted nematode eggs on both grids, and the number obtained was multiplied by 50 to calculate the number of eggs per gram of faeces [Foreyt, 2013]. Conversely, we counted protozoan cysts on only 2 lines of a grid because of their elevated concentrations: the results were multiplied by 300 ( 2 lines $\times 6=12$ lines, 12 lines $\times 50=300$ ) to obtain the number of cysts per gram of faeces. All coproscopical analyses were performed by 2 experimented observers at the same time. Consensus was obtained for each slide.

Statistical Analyses

First, we compared the number of parasite taxa detected by each method. Then, for each parasite taxon, we compared the probability of detection associated with each of the 4 different methods used. Finally, we quantitatively compared the 3 different flotation solutions in their ability to recover eggs and cysts. We performed Wilcoxon signed-rank tests for all these analyses (SAS version 9.3, proc univariate).

\section{Results}

We showed that overall, SF-Mc-zinc revealed significantly more parasite taxa (mean \pm SD: $2.60 \pm 0.91$ ) than the other 3 methods (sedimentation: $2.19 \pm 1.06$; SFMc-sugar: $2.13 \pm 1.00$; SF-Mc-salt: $0.79 \pm 0.77$; Tables 1,2$)$. SF-Mc-salt also revealed significantly fewer parasite taxa than the other 3 methods, and the difference between SF-Mc-sugar and the sedimentation was not significant (Tables 1, 2). Additionally, with SF-Mc-zinc, damaged protozoan cysts that looked like truncated or deflated bal- 
Table 1. Positivity rates of the 47 faecal samples used for the 4 coproscopical methods

\begin{tabular}{|c|c|c|c|c|c|}
\hline \multirow[t]{2}{*}{ Parasite taxa } & \multirow{2}{*}{$\begin{array}{l}\text { Positivity } \\
\text { rates in relation } \\
\text { to the total } \\
\text { number of } \\
\text { faecal samples } \\
\text { collected }\end{array}$} & \multicolumn{4}{|c|}{$\begin{array}{l}\text { Positivity rates in relation to the } \\
\text { methods }\end{array}$} \\
\hline & & $\begin{array}{l}\text { sedimen- } \\
\text { tation }\end{array}$ & $\begin{array}{l}\text { SF-Mc- } \\
\text { zinc }\end{array}$ & $\begin{array}{l}\text { SF-Mc- } \\
\text { sugar }\end{array}$ & $\begin{array}{l}\text { SF-Mc- } \\
\text { salt }\end{array}$ \\
\hline N. americanus/Oesophagostomum sp. complex & 0.68 & 0.34 & 0.68 & 0.62 & 0.53 \\
\hline Strongyloides sp. & 0.43 & 0.21 & 0.38 & 0.30 & 0.21 \\
\hline Balantidium coli & 0.85 & 0.72 & 0.72 & 0.11 & 0.00 \\
\hline Entamoeba coli & 0.94 & 0.64 & 0.79 & 0.70 & 0.02 \\
\hline
\end{tabular}

Table 2. Results of Wilcoxon signed-rank tests comparing the number of parasite taxa detected across the 4 methods

\begin{tabular}{lrc}
\hline Pairwise comparisons & $\mathrm{V}$ & $p$ \\
\hline Sedimentation/zinc sulphate & 82 & 0.01 \\
Sedimentation/salt & 764 & $<0.0001$ \\
Sedimentation/sugar & 374 & 0.73 \\
Sugar/salt & 0 & $<0.0001$ \\
Salt/zinc sulphate & 0 & $<0.0001$ \\
Sugar/zinc sulphate & 117 & $<0.01$ \\
\hline
\end{tabular}

loons were sometimes found (Fig. 1). This distortion did not cause, however, any difficulties for diagnosis because the refractivity and diameter of the protozoan cysts were conserved.

Regarding the probability of detection of each parasite taxon, SF-Mc-zinc was generally better to detect all 4 studied parasite taxa than any other methods (Table 3; Fig. 2). However, SF-Mc-sugar solution was equally good at detecting eggs of both nematode species and cysts of $E$. coli as SF-Mc-zinc was. Finally, the sedimentation method was also equally good as SF-Mc-zinc to detect cysts of $B$. coli.

Finally, when comparing the quantity of eggs retrieved in the 3 flotation solutions, we found that while SF-Mc-zinc was again the best method to retrieve a higher number of both protozoan species, SF-Mc-sugar and SF-Mc-zinc allowed the retrieval of more eggs of the complex N. americanus/Oesophagostomum sp. than SF-Mc-salt. The 3 flotation solutions gave, however, equivalent results in their ability to recover eggs of Strongyloides sp. (Table 4).

\section{Discussion}

In this study, we compared the ability of 4 different coproscopical methods to retrieve parasite forms in a free-ranging, non-provisioned population of a primate species. We first showed that SF-Mc-zinc and to a lesser extent SF-Mc-sugar were valuable for studying zoonotic enteric parasites in mandrills. Additionally, we pro- 

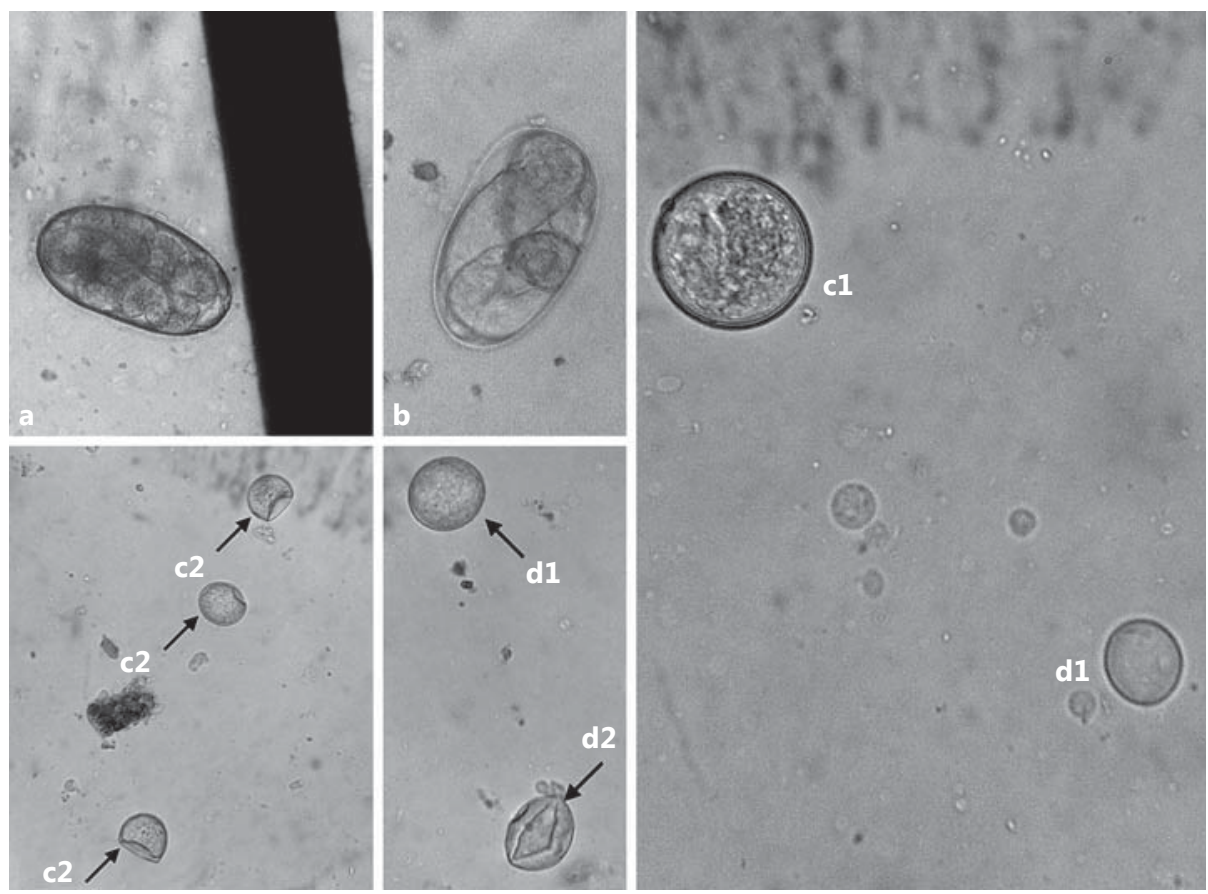

Fig. 1. Eggs and cysts recovered with the SF-Mc method. a Necator americanus/Oesophagostomum sp. complex egg. b Strongyloides sp. egg. c1 Balantidium coli cyst. c2 Balantidium coli damaged cyst (SF-Mc-zinc). d1 Entamoeba coli cyst. d2 Entamoeba coli damaged cyst (SF-Mc-zinc).

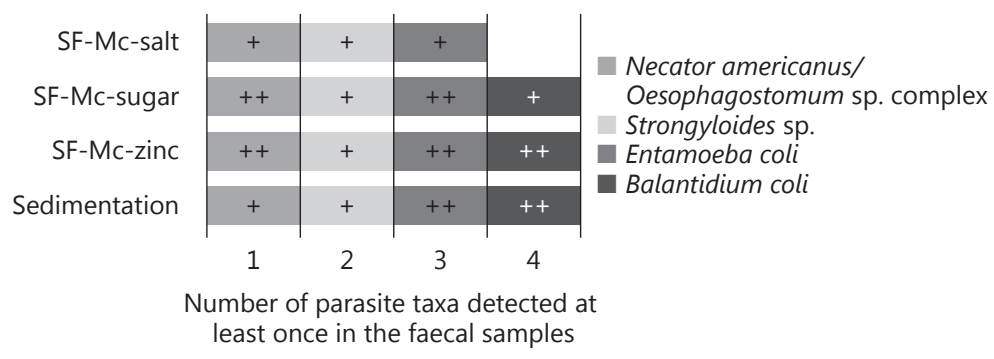

Fig. 2. Comparison of the probability of detection of each studied parasite taxon. For each taxon, the same number of " + " symbols indicates that the probability of detection is statistically equal using both techniques, whereas a higher number of "+" symbols indicates that the probability of detection is significantly superior with this technique. 
Table 3. Results of Wilcoxon signed-rank tests comparing the probability of detection of each studied parasite and associated probabilities across the 4 methods

\begin{tabular}{|c|c|c|c|c|c|c|c|}
\hline \multirow[t]{2}{*}{ Parasite taxa } & \multirow[t]{2}{*}{ Pairwise comparisons } & \multirow[t]{2}{*}{$\mathrm{V}$} & \multirow[t]{2}{*}{$p$} & \multicolumn{4}{|c|}{ Probability of detection } \\
\hline & & & & $\begin{array}{l}\text { sedimen- } \\
\text { tation }\end{array}$ & $\begin{array}{l}\text { SF-Mc- } \\
\text { zinc }\end{array}$ & $\begin{array}{l}\text { SF-Mc- } \\
\text { sugar }\end{array}$ & $\begin{array}{l}\text { SF-Mc- } \\
\text { salt }\end{array}$ \\
\hline \multirow{6}{*}{$\begin{array}{l}\text { Necator americanus/ } \\
\text { Oesophagostomum sp. } \\
\text { complex }\end{array}$} & Sedimentation/zinc sulphate & 9.5 & $<0.001$ & 0.34 & 0.68 & 0.62 & 0.53 \\
\hline & Sedimentation/salt & 50 & 0.04 & & & & \\
\hline & Sedimentation/sugar & 44 & $<0.01$ & & & & \\
\hline & Zinc sulphate/sugar & 12 & 0.23 & & & & \\
\hline & Zinc sulphate/salt & 28 & 0.01 & & & & \\
\hline & Salt/sugar & 18 & 0.13 & & & & \\
\hline \multirow[t]{6}{*}{ Strongyloides sp. } & Sedimentation/zinc sulphate & 13 & 0.02 & 0.21 & 0.38 & 0.30 & 0.21 \\
\hline & Sedimentation/salt & 18 & 1 & & & & \\
\hline & Sedimentation/sugar & 9 & 0.18 & & & & \\
\hline & Zinc sulphate/sugar & 18 & 0.13 & & & & \\
\hline & Zinc sulphate/salt & 50 & 0.01 & & & & \\
\hline & Salt/sugar & 18 & 0.13 & & & & \\
\hline \multirow[t]{6}{*}{ Balantidium coli } & Sedimentation/zinc sulphate & 28 & 1 & 0.72 & 0.72 & 0.11 & 0 \\
\hline & Sedimentation/salt & 595 & $<0.0001$ & & & & \\
\hline & Sedimentation/sugar & 527 & $<0.0001$ & & & & \\
\hline & Zinc sulphate/sugar & 480 & $<0.0001$ & & & & \\
\hline & Zinc sulphate/salt & 595 & $<0.0001$ & & & & \\
\hline & Salt/sugar & 15 & 0.04 & & & & \\
\hline \multirow[t]{6}{*}{ Entamoeba coli } & Sedimentation/zinc sulphate & 20 & 0.06 & 0.64 & 0.79 & 0.70 & 0.02 \\
\hline & Sedimentation/salt & 480 & $<0.0001$ & & & & \\
\hline & Sedimentation/sugar & 80 & 0.51 & & & & \\
\hline & Zinc sulphate/sugar & 68 & 0.30 & & & & \\
\hline & Zinc sulphate/salt & 666 & $<0.0001$ & & & & \\
\hline & Salt/sugar & 528 & $<0.0001$ & & & & \\
\hline
\end{tabular}

vided the first evidence that SF-Mc-zinc may be used to detect and, as a consequence, to quantify protozoan cysts of $B$. coli and E. coli. An accurate quantification of these large protozoan species still needs, however, several methodological validations such as interobserver reliability tests (in our case, 2 observers read the same slides).

Second, we also found that SF-Mc-zinc allows the detection of more different parasite taxa than sedimentation did. This result may be related to the presence of more debris on the sedimentation slide because of a lower dilution ( $1 \mathrm{~g}$ faecal material $/ 6 \mathrm{~mL}$ ) than on the McMaster slide where dilution was higher ( $1 \mathrm{~g}$ faecal materi$\mathrm{al} / 15 \mathrm{~mL}$ ). Moreover, if an appropriate flotation medium is used, most vegetal debris should fall to the bottom of McMaster counting chambers, facilitating the reading on both grids. Increasing the dilution when using the sedimentation method would have possibly led to a better sensitivity of the method.

The different flotation solutions used appear to show large differences in their recovery/detection rates. A limiting factor possibly explaining these contrasts found across flotation techniques is the time span between loading the McMaster chambers 
Table 4. Results of Wilcoxon signed-rank tests comparing the number of eggs/cysts per gram of faeces (with the associated means of occurrence) across the 3 flotation methods

\begin{tabular}{|c|c|c|c|c|c|c|}
\hline \multirow[t]{2}{*}{ Parasite taxa } & \multirow{2}{*}{$\begin{array}{l}\text { Pairwise } \\
\text { comparisons }\end{array}$} & \multirow[t]{2}{*}{ V } & \multirow[t]{2}{*}{$p$} & \multicolumn{3}{|c|}{ Mean of eggs/cysts per gram of faeces \pm SD } \\
\hline & & & & SF-Mc-zinc & SF-Mc-sugar & SF-Mc-salt \\
\hline $\begin{array}{l}\text { Necator americanus/ } \\
\text { Oesophagostomum sp. } \\
\text { complex }\end{array}$ & $\begin{array}{l}\text { Zinc sulphate/salt } \\
\text { Zinc sulphate/sugar } \\
\text { Salt/sugar }\end{array}$ & $\begin{array}{l}278 \\
180 \\
104\end{array}$ & $\begin{array}{l}0.04 \\
0.18 \\
0.01\end{array}$ & $205.32 \pm 284.04$ & $236.17 \pm 321.80$ & $145.74 \pm 206.64$ \\
\hline Strongyloides sp. & $\begin{array}{l}\text { Zinc sulphate/salt } \\
\text { Zinc sulphate/sugar } \\
\text { Salt/sugar }\end{array}$ & $\begin{array}{r}107 \\
101 \\
39\end{array}$ & $\begin{array}{l}0.36 \\
0.26 \\
0.678\end{array}$ & $63.83 \pm 110.68$ & $44.68 \pm 77.48$ & $48.94 \pm 129.17$ \\
\hline Balantidium coli & $\begin{array}{l}\text { Zinc sulphate/salt } \\
\text { Zinc sulphate/sugar } \\
\text { Salt/sugar }\end{array}$ & $\begin{array}{r}595 \\
546 \\
0\end{array}$ & $\begin{array}{c}<0.0001 \\
<0.0001 \\
0.05\end{array}$ & $887.23 \pm 1,307.61$ & $44.68 \pm 152.95$ & 0.00 \\
\hline Entamoeba coli & $\begin{array}{l}\text { Zinc sulphate/salt } \\
\text { Zinc sulphate/sugar } \\
\text { Salt/sugar }\end{array}$ & $\begin{array}{r}666 \\
818 \\
0\end{array}$ & $\begin{array}{l}<0.0001 \\
<0.0001 \\
<0.0001\end{array}$ & $7,123.40 \pm 8,829.13$ & $600.00 \pm 699.38$ & $6.38 \pm 43.76$ \\
\hline
\end{tabular}

and counting the parasite forms [Ballweber et al., 2014]. In this study, a 5-min timeframe was chosen. While most other studies used a 5- to 10-min timeframe, the optimal interval appears sometimes to be higher (30 min for Heligmosomoides sp. [Dunn and Keymer, 1986]). Additionally, sugar solutions, which have higher viscosity, have been suggested to require longer standing time compared to others [Broussard, 2003].

We further expected that higher quantities of parasite eggs and cysts would be recovered with sugar solution because its SG (1.27) was higher than that of zinc sulphate solution (1.18) or salt solution (1.18). As such, sugar solution allowed better retrieval of eggs of the N. americanus/Oesophagostomum sp. complex. However, we found that protozoan cysts are better recovered using SF-Mc-zinc, highlighting the possibility that other factors than SG play a role in recovering parasites, such as faeces moisture, lipid richness, amount of debris or even storage conditions [Ballweber et al., 2014]. To avoid such biases, we performed intrasample comparisons, but these parameters should be taken into account when making intersample comparisons. The fact that SF-Mc-zinc performed better in retrieving protozoan cysts than SF-Mcsalt and SF-Mc-sugar is in contradiction with previous studies in dairy cattle. The recovery efficiency for Cryptosporidium parvum oocysts is better using a flotation with a salt solution than with a sugar solution [Kar et al., 2011]. These contrasted results across species suggest that extrapolations to other study systems are not always possible.

Although SF-Mc-zinc was our preferred method, its main drawback was that we found a high proportion ( $>50 \%)$ of damaged protozoan cysts. Other studies have also used flotation methods to detect protozoan cysts and oocysts of, e.g., Giardia cysts [Zajac et al., 2002], Cryptosporidia [Peter et al., 2015], or Eimeria [Zenner et al., 2002; Richard, 2012; Hu et al., 2016]. Zinc sulphate solution is known for distorting most helminth eggs. However, sugar solution also tends to distort Giardia cysts, whereas zinc sulphate is considered ideal for their isolation [Broussard, 2003]. Particular attention should therefore be paid to these variations regarding the integrity of some 
parasite forms in order to avoid both false negatives and false positives. In this study, damaged B. coli and E. coli cysts kept their refractivity and diameters so that their diagnoses were still possible. Another limitation when using SF-Mc in general to study protozoan cysts is the impossibility of diagnosing small cysts accurately, since the $\times 100$ lens would break the thick upper plate of the McMaster slide. As such, small amoebas like the Entamoeba histolyticaldispar complex or Endolimax nana cannot be unambiguously diagnosed. In these cases, sedimentation techniques remain the most appropriate ones.

Whether one method should be preferred to another depends on the question asked. For qualitative measurements involving, for example, an adapted medical treatment, the method allowing the detection of the widest range of parasite taxa should be preferred. SF-Mc-zinc should therefore be chosen. By contrast, if quantitative measurements are sought to compare parasite loads across individuals or to evaluate excretion levels, then the method allowing a higher detection of a given parasite species should be selected. SF-Mc-zinc should again be favoured. SF-Mc methods have been criticized when treatment decisions were needed, because their predictive value is near zero when animals are only slightly parasitized: at low egg count $(<50$ eggs/g), these methods generally yield poor results regarding the probability of detection of parasites [Egwang and Slocombe, 1981; Rinaldi et al., 2011]. Consequently, in these cases when precise quantification is not needed while high sensitivity is necessary to avoid false negatives, sedimentation methods should be favoured.

Studies on simian gastrointestinal parasitism often use several coproscopical methods at the same time [Mbaya and Udendeye, 2011; Helenbrook et al., 2015; Kouassi et al., 2015; Li et al., 2015] and/or molecular analyses to improve parasite detection [Cibot et al., 2015]. Few studies use only SF-Mc-zinc (e.g., see Mutani et al., 2003). According to our findings, we would recommend, however, to use this method alone if looking for a field-friendly method, especially when studying large gastrointestinal parasites (nematodes and large protozoan) in species sharing similar characteristics with mandrills. Indeed and as mentioned above, the SF-Mc-zinc method may vary depending on host diet and living conditions. Caution is necessary to generalize our findings to other non-human primate species and when looking for other parasites than the ones studied here.

Other coproscopical methods than the 4 tested are also regularly used in studies comparing methods or studying animal parasitism. For example, the DCF method (SF with a first step of centrifugation) using Sheather's sugar is considered as the gold standard method for detecting most veterinary helminth eggs and coccidian oocysts [Broussard, 2003]. Moreover, the DCF method using a sugar solution has been documented as being more suitable for the detection of Platynosomum sp. (trematode) in cats than sedimentation methods [Rocha et al., 2014]. Therefore, a first centrifugal step might have led to better results when using SF-Mc-sugar. The advantages of an initial centrifugation step have been largely documented [Egwang and Slocombe, 1981; Zajac et al., 2002; Broussard, 2003]. In other cases though, SF-Mc methods provided more accurate measurements of strongyle eggs in cattle and sheep faecal material compared to a modification of the Stoll method [Stoll, 1930], which is a DCF method [Ballweber et al., 2014]. Modified methods, combining flotation and sedimentation, have also been tested: the prevalence of Anoplocephala perfoliata in horses' faecal samples is significantly higher using a modified sedimentation-flotation method (50-g faeces samples, flotation solution-saturated $\mathrm{NaCl}$ and sucrose; SG: 1.25) than SF-Mc methods 
[Tomczuk et al., 2014], and a simple sedimentation together with the modified zinc sulphate flotation method would improve the diagnosis of nematode eggs and protozoan cysts in dog faeces [Cöplü et al., 2007]. Regarding the complementary advantages highlighted in this study of both the sedimentation technique and the SF-Mc-zinc method, the use of such modified methods would be worth studying for their ability to detect simian gastrointestinal parasites. Comparisons of the efficiency of different coproscopical methods constitute a useful and necessary methodological basis to set up e.g., epidemiological surveys. In this study, we compared the value of 4 different coproscopical methods in detecting 4 gastrointestinal parasites of known zoonotic potential in a free-ranging population of a primate species. We first showed that SF-Mczinc and to a lesser extent SF-Mc-sugar are valuable methods for studying gastrointestinal parasitism in mandrills. The choice of SF-Mc-zinc (i.e., zinc sulphate simple flotation coupled with a McMaster method) appears to be the most relevant method when studying zoonotic simian gastrointestinal large parasites (nematode eggs and large protozoan cysts). Additionally, we provided the first evidence that this method may be used to detect and quantify large protozoan cysts such as B. coli and E. coli.

\section{Acknowledgements}

The work was conducted in Lekedi Park, Bakoumba, Gabon, within the framework of the Mandrillus Project, director: M.J.E. Charpentier, Institut des Sciences de l'Evolution de Montpellier. We are grateful to past and present staff of the Mandrillus Project for their involvement in data collection. We are also grateful to the COMILOG-ERAMET group for their logistical support. We thank M. Bridou and I. Nicholson (Ecole Nationale Vétérinaire de Nantes) for their proofreading. The Mandrillus Project is funded by a grant from the Deutsche Forschungsgemeinschaft (DFG, KA 1082-20-1), a "Station d'Etudes en Ecologie Globale" (INEE-CNRS), a "Laboratoire International Associé" (CIRMF and INEE-CNRS) and a PEPS "Ecosan" (INEE-CNRS) to M.J.E.C., that all allowed us to carry out this study. This study was authorized by the CENAREST institute. This is a Project Mandrillus publication number 15 and an ISEM 2017-241-SUD.

\section{Disclosure Statement}

The authors certify that they have no affiliations with or involvement in any organization or entity with any financial interest, or non-financial interest in the subject matter or materials discussed in this paper.

\section{References}

Arean VM, Koppisch E (1956). Balantidiasis: a review and report of cases. American Journal of Pathology 32: 1089-1115.

Ashford RW, Reid GD, Butynski TM (1990). The intestinal faunas of man and mountain gorillas in a shared habitat. Annals of Tropical Medicine and Parasitology 84: 337-340.

Ashford RW, Reid GD, Wrangham RW (2000). Intestinal parasites of the chimpanzee Pan troglodytes in Kibale Forest, Uganda. Annals of Tropical Medicine and Parasitology 94: 173-179.

Ballweber LR, Beugnet F, Marchiondo AA, Payne PA (2014). American Association of Veterinary Parasitologists' review of veterinary fecal flotation methods and factors influencing their accuracy and use - is there really one best technique? Veterinary Parasitology 204: 73-80.

Barda BD, Rinaldi L, Ianniello D, Zepherine H, Salvo F, Sadutshang T, et al (2013). Mini-FLOTAC, an innovative direct diagnostic technique for intestinal parasitic infections: experience from the field. PLoS Neglected Tropical Diseases 7: e2344. 
Becker A-C, Kraemer A, Epe C, Strube C (2016). Sensitivity and efficiency of selected coproscopical methods - sedimentation, combined zinc sulfate sedimentation-flotation, and McMaster method. Parasitology Research 115: 2581-2587.

Becker SL, Lohourignon LK, Speich B, Rinaldi L, Knopp S, N'Goran EK, et al (2011). Comparison of the Flotac-400 dual technique and the formalin-ether concentration technique for diagnosis of human intestinal protozoon infection. Journal of Clinical Microbiology 49: 2183-2190.

Benavides JA, Huchard E, Pettorelli N, King AJ, Brown ME, Archer CE, et al (2012). From parasite encounter to infection: multiple-scale drivers of parasite richness in a wild social primate population. American Journal of Physical Anthropology 147: 52-63.

Brockmeyer T, Kappeler PM, Willaume E, Benoit L, Mboumba S, Charpentier MJE (2015). Social organization and space use of a wild mandrill (Mandrillus sphinx) group. American Journal of Primatology 77: $1036-1048$.

Broussard JD (2003). Optimal fecal assessment. Clinical Techniques in Small Animal Practice 18: 218-230.

Burgos-Rodriguez AG (2011). Zoonotic diseases of primates. Veterinary Clinics of North America: Exotic Animal Practice 14: 557-575.

Centers for Disease Control and Prevention (2016a). Balantidiasis (also known as Balantidium coli infection). http://www.cdc.gov/parasites/balantidium/index.html (accessed February 13, 2017).

Centers for Disease Control and Prevention (2016b). Hookworm - general information. http://www.cdc. gov/parasites/hookworm/gen_info/faqs.html (accessed March 22, 2017).

Centers for Disease Control and Prevention (2016c). Strongyloides - general information. http://www. cdc.gov/parasites/strongyloides/gen_info/faqs.html (accessed March 24, 2017).

Chakraborty D, Tiwari S, Reddy DM, Umapathy G (2016). Prevalence of gastrointestinal parasites in civets of fragmented rainforest patches in Anamalai Hills, Western Ghats, India. Journal of Parasitology 102: 463-467.

Cibot M, Guillot J, Lafosse S, Bon C, Seguya A, Krief S (2015). Nodular worm infections in wild non-human primates and humans living in the Sebitoli Area (Kibale National Park, Uganda): do high spatial proximity favor zoonotic transmission? PLoS Neglected Tropical Diseases 9: e0004133.

Coles GC, Bauer C, Borgsteede FHM, Geerts S, Klei TR, Taylor MA, et al (1992). World Association for the Advancement of Veterinary Parasitology (WAAVP) methods for the detection of anthelmintic resistance in nematodes of veterinary importance. Veterinary Parasitology 44: 35-44.

Cöplü N, Gözalan A, Akin L (2007). The comparison of the concentration techniques used in investigation of feces for parasitosis. Turkiye Parazitolojii Dergisi 31: 123-128.

Crawley JAH, Chapman SN, Lummaa V, Lynsdale CL (2016). Testing storage methods of faecal samples for subsequent measurement of helminth egg numbers in the domestic horse. Veterinary Parasitology 221: 130-133.

Da Silva AS, Zanette RA, Otto MA, Soares CDM, Alves SH, Monteiro SG, et al (2009). Duddingtonia flagrans: centrifugal flotation technique with magnesium sulphate for the quantification and qualification of chlamydospores in sheep faeces. Experimental Parasitology 121: 187-188.

Deluol A-M (1988). Atlas de parasitologie: guide pratique du diagnostique au microscope. Paris, Varia.

Dunn A, Keymer A (1986). Factors affecting the reliability of the McMaster technique. Journal of Helminthology 60: 260-262.

Ebbert MA, McGrew WC, Marchant LF (2015). Differences between chimpanzee and baboon gastrointestinal parasite communities. Parasitology 142: 958-967.

Egwang TG, Slocombe JO (1981). Efficiency and sensitivity of techniques for recovering nematode eggs from bovine feces. Canadian Journal of Comparative Medicine: Revue Canadienne de Médecine Comparée 45: 243-248.

Euzeby J (1982). Experimental Diagnosis of Animal Helminthiases (Domestic Animals - Laboratory Animals - Primates). Practical Work in Veterinary Helminthology, vol II, p 364. Paris, Informations Techniques des Services Vétérinaires, Ministère de l'Agriculture.

Foreyt WJ (2013). Veterinary Parasitology Reference Manual. New York, Wiley \& Sons.

Galinski MR, Barnwell JW (2009). Monkey malaria kills four humans. Trends in Parasitology 25: 200-204.

Georgiev VS (2000). Necatoriasis: treatment and developmental therapeutics. Expert Opinion on Investigational Drugs 9: 1065-1078.

Ghai RR, Chapman CA, Omeja PA, Davies TJ, Goldberg TL (2014). Nodule worm infection in humans and wild primates in Uganda: cryptic species in a newly identified region of human transmission. PLoS Neglected Tropical Diseases 8: e2641.

Gillespie TR (2006). Noninvasive assessment of gastrointestinal parasite infections in free-ranging primates. International Journal of Primatology 27: 1129.

Gotfred-Rasmussen H, Lund M, Enemark HL, Erlandsen M, Petersen E (2016). Comparison of sensitivity and specificity of 4 methods for detection of Giardia duodenalis in feces: immunofluorescence and PCR are superior to microscopy of concentrated iodine-stained samples. Diagnostic Microbiology and Infectious Disease 84: 187-190. 
Great Britain Ministry of Agriculture, Fisheries and Food (1971). Manual of Veterinary Parasitological Laboratory Techniques. London, H.M. Stationery Office.

Greger M (2007). The human/animal interface: emergence and resurgence of zoonotic infectious diseases. Critical Reviews in Microbiology 33: 243-299.

Hasegawa H, Modrý D, Kitagawa M, Shutt KA, Todd A, Kalousová B, et al (2014). Humans and great apes cohabiting the forest ecosystem in Central African Republic harbour the same hookworms. PLoS Neglected Tropical Diseases 8: e2715.

Helenbrook WD, Wade SE, Shields WM, Stehman SV, Whipps CM (2015). Gastrointestinal parasites of Ecuadorian mantled howler monkeys (Alouatta palliata aequatorialis) based on fecal analysis. Journal of Parasitology 101: 341-350.

Henriksen SA, Aagaard K (1976). A simple flotation and McMaster method. Nordisk Veterinaermedicin 28: 392-397.

Hu XL, Liu G, Wang WX, Zhou R, Liu SQ, Li LH, et al (2016). Methods of preservation and flotation for the detection of nematode eggs and coccidian oocysts in faeces of the forest musk deer. Journal of Helminthology 90: 680-684.

Hyuga A, Matsumoto J (2016). A survey of gastrointestinal parasites of alpacas (Vicugna pacos) raised in Japan. Journal of Veterinary Medical Science 78: 719-721.

Jolles AE, Ezenwa VO, Etienne RS, Turner WC, Olff H (2008). Interactions between macroparasites and microparasites drive infection patterns in free-ranging African buffalo. Ecology 89: 2239-2250.

Kar S, Gawlowska S, Daugschies A, Bangoura B (2011). Quantitative comparison of different purification and detection methods for Cryptosporidium parvum oocysts. Veterinary Parasitology 177: 366-370.

Keita MB, Hamad I, Bittar F (2014). Looking in apes as a source of human pathogens. Microbial Pathogenesis 77: 149-154.

Köndgen S, Kühl H, N'Goran PK, Walsh PD, Schenk S, Ernst N, et al (2008). Pandemic human viruses cause decline of endangered great apes. Current Biology 18: 260-264.

Kouassi RYW, McGraw SW, Yao PK, Abou-Bacar A, Brunet J, Pesson B, et al (2015). Diversity and prevalence of gastrointestinal parasites in seven non-human primates of the Taï National Park, Côte d'Ivoire. Parasite. 22. DOI: 10.1051/parasite/2015001.

Krief S, Jamart A, Mahé S, Leendertz FH, Mätz-Rensing K, Crespeau F, et al (2008). Clinical and pathologic manifestation of oesophagostomosis in African great apes: does self-medication in wild apes influence disease progression? Journal of Medical Primatology 37: 188-195.

Krief S, Vermeulen B, Lafosse S, Kasenene JM, Nieguitsila A, Berthelemy M, et al (2010). Nodular worm infection in wild chimpanzees in western Uganda: a risk for human health? PLoS Neglected Tropical Diseases 4: e0000630.

Legesse M, Erko B (2004). Zoonotic intestinal parasites in Papio anubis (baboon) and Cercopithecus aethiops (vervet) from four localities in Ethiopia. Acta Tropica 90: 231-236.

Levecke B, Dorny P, Geurden T, Vercammen F, Vercruysse J (2007). Gastrointestinal protozoa in nonhuman primates of four zoological gardens in Belgium. Veterinary Parasitology 148: 236-246.

Levecke B, Dorny P, Vercammen F, Visser LG, Van Esbroeck M, Vercruysse J, et al (2015). Transmission of Entamoeba nuttalli and Trichuris trichiura from nonhuman primates to humans. Emerging Infectious Diseases 21: 1871-1872.

Li L, Kapoor A, Slikas B, Bamidele OS, Wang C, Shaukat S, et al (2010). Multiple diverse circoviruses infect farm animals and are commonly found in human and chimpanzee feces. Journal of Virology 84: $1674-1682$.

Li M, Zhao B, Li B, Wang Q, Niu L, Deng J, et al (2015). Prevalence of gastrointestinal parasites in captive non-human primates of twenty-four zoological gardens in China. Journal of Medical Primatology 44: $168-173$.

Lynsdale CL, Santos DJFD, Hayward AD, Mar KU, Htut W, Aung HH, et al (2015). A standardised faecal collection protocol for intestinal helminth egg counts in Asian elephants, Elephas maximus. International Journal for Parasitology Parasites and Wildlife 4: 307-315.

Mati VLT, Raso P, de Melo AL (2014). Strongyloides stercoralis infection in marmosets: replication of complicated and uncomplicated human disease and parasite biology. Parasites and Vectors 7: 579. https://doi.org/10.1186/s13071-014-0579-2.

Mbaya AW, Udendeye UJ (2011). Gastrointestinal parasites of captive and free-roaming primates at the Afi Mountain Primate Conservation Area in Calabar, Nigeria and their zoonotic implications. $\mathrm{Pa}$ kistan Journal of Biological Sciences 14: 709-714.

Miller RE, Fowler ME (2014). Fowler's Zoo and Wild Animal Medicine. Amsterdam, Elsevier Health Sciences.

Mossoun A, Pauly M, Akoua-Koffi C, Couacy-Hymann E, Leendertz SAJ, Anoh AE, et al (2015). Contact to non-human primates and risk factors for zoonotic disease emergence in the Taï region, Côte d'Ivoire. EcoHealth 12: 580-591.

Mutani A, Rhynd K, Brown G (2003). A preliminary investigation on the gastrointestinal helminths of the Barbados green monkey, Cercopithecus aethiops sabaeus. Revista do Instituto de Medicina Tropical de São Paulo 45: 193-195. 
Muyembe-Tamfum JJ, Mulangu S, Masumu J, Kayembe JM, Kemp A, Paweska JT (2012). Ebola virus outbreaks in Africa: past and present. Onderstepoort Journal of Veterinary Research 79: 451. http:// dx.doi.org/10.4102/ojvr.v79i2.451.

Narat V, Guillot J, Pennec F, Lafosse S, Grüner AC, Simmen B, et al (2015). Intestinal helminths of wild bonobos in forest-savanna mosaic: risk assessment of cross-species transmission with local people in the Democratic Republic of the Congo. EcoHealth 12: 621-633.

Peignot P, Charpentier MJE, Bout N, Bourry O, Massima U, Dosimont O, et al (2008). Learning from the first release project of captive-bred mandrills Mandrillus sphinx in Gabon. Oryx 42: 122-131.

Peter GS, Gitau GK, Mulei CM, Vanleeuwen J, Richards S, Wichtel J, et al (2015). Prevalence of Cryptosporidia, Eimeria, Giardia, and Strongyloides in pre-weaned calves on smallholder dairy farms in Mukurwe-ini district, Kenya. Veterinary World 8: 1118-1125.

Poirotte C (2016). Parasite Avoidance Strategies in a Natural Population of a Social Primate. Montpellier, Université Montpellier-II.

Poirotte C, Basset D, Willaume E, Makaba F, Kappeler PM, Charpentier MJE (2016). Environmental and individual determinants of parasite richness across seasons in a free-ranging population of mandrills (Mandrillus sphinx). American Journal of Physical Anthropology 159: 442-456.

Quinn R, Smith HV, Bruce RG, Girdwood RW (1980). Studies on the incidence of Toxocara and Toxascaris spp. ova in the environment. 1. A comparison of flotation procedures for recovering Toxocara spp. ova from soil. Journal of Hygiene 84: 83-89.

Richard F (2012). Comparaison de différents liquides de flottation en coproscopie des ruminants. Thesis, Université Claude-Bernard, Lyon.

Rinaldi L, Coles GC, Maurelli MP, Musella V, Cringoli G (2011). Calibration and diagnostic accuracy of simple flotation, McMaster and FLOTAC for parasite egg counts in sheep. Veterinary Parasitology 177: 345-352.

Rocha NO, Portela RW, Camargo SS, Souza WR, Carvalho GC, Bahiense TC (2014). Comparison of two coproparasitological techniques for the detection of Platynosomum sp. infection in cats. Veterinary Parasitology 204: 392-395.

Rwego IB, Isabirye-Basuta G, Gillespie TR, Goldberg TL (2008). Gastrointestinal bacterial transmission among humans, mountain gorillas, and livestock in Bwindi Impenetrable National Park, Uganda. Conservation Biology 22: 1600-1607.

Schuster FL, Ramirez-Avila L (2008). Current world status of Balantidium coli. Clinical Microbiology Reviews 21: 626-638.

Schuster FL, Visvesvara GS (2004). Amebae and ciliated protozoa as causal agents of waterborne zoonotic disease. Veterinary Parasitology 126: 91-120.

Sharp PM, Hahn BH (2011). Origins of HIV and the AIDS pandemic. Cold Spring Harbor Perspectives in Medicine 1: a006841.

Standley CJ, Mugisha L, Dobson AP, Stothard JR (2012). Zoonotic schistosomiasis in non-human primates: past, present and future activities at the human-wildlife interface in Africa. Journal of Helminthology 86: 131-140.

Stoll NR (1930). On methods of counting nematode ova in sheep dung. Parasitology 22: 116-136.

Thienpont D, Rochette F, Vanparijs OFJ (1986). Diagnosing Helminthiasis by Coprological Examination. Beerse, Janssen Research Foundation.

Thompson RCA, Smith A (2011). Zoonotic enteric protozoa. Veterinary Parasitology 182: 70-78.

Toledo R, Muñoz-Antoli C, Esteban J-G (2015). Strongyloidiasis with emphasis on human infections and its different clinical forms. Advances in Parasitology 88: 165-241.

Tomczuk K, Kostro K, Szczepaniak KO, Grzybek M, Studzińska M, Demkowska-Kutrzepa M, et al (2014). Comparison of the sensitivity of coprological methods in detecting Anoplocephala perfoliata invasions. Parasitology Research 113: 2401-2406.

Vadlamudi RS, Chi DS, Krishnaswamy G (2006). Intestinal strongyloidiasis and hyperinfection syndrome. Clinical and Molecular Allergy 4: 8.

Whittier CA, Nutter FB, Stoskopf M (2000). Zoonotic disease concerns in primate field settings. The Apes: Challenges for the 21st Century, Conference Proceedings, Brookfield, pp 232-237.

Wolf TM, Sreevatsan S, Travis D, Mugisha L, Singer RS (2014). The risk of tuberculosis transmission to free-ranging great apes. American Journal of Primatology 76: 2-13.

Wolfe ND, Escalante AA, Karesh WB, Kilbourn A, Spielman A, Lal AA (1998). Wild primate populations in emerging infectious disease research: the missing link? Emerging Infectious Diseases 4: 149-158.

Yelifari L, Bloch P, Magnussen P, van Lieshout L, Dery G, Anemana S, et al (2005). Distribution of human Oesophagostomum bifurcum, hookworm and Strongyloides stercoralis infections in northern Ghana. Transactions of the Royal Society of Tropical Medicine and Hygiene 99: 32-38.

Zajac AM, Johnson J, King SE (2002). Evaluation of the importance of centrifugation as a component of zinc sulfate fecal flotation examinations. Journal of the American Animal Hospital Association 38: 221-224.

Zenner L, Gounel JM, Chauve CM (2002). A standardized method for detecting parasite eggs and oocysts in soils. Revue de médecine vétérinaire 153: 729-734. 